\title{
LA BÚSQUEDA DE UN LUGAR SAGRADO: LA TRAYECTORIA SOCIAL Y RELIGIOSA DE LOS POBLADORES EN CHILE 1962-1992.
}

\author{
MAXIMILIANO SALINAS
}

\section{Introducción.}

Hablando sobre la identidad de los sectores populares chilenos señaló el historiador Mario Góngora en 1980: «»La cultura popular sigue entretanto su curso intemporal, sujeto a sus propias leyes»(1). ¿Cómo reconocer ese curso y esas leyes propias?.

La historia de la cultura popular y de los pobladores, en particular, es una historia religiosa entendida como el tránsito de lo profano a lo sagrado, de la muerte a la vida, del no-ser al ser. Los pobladores, o habitantes pobres de la ciudad, constituyen una sociedad particularmente religiosa en términos de su sed de ser. Como escribiera Eliade: «El hombre religioso está sediento de ser, el terror ante el caos que rodea su mundo habitado corresponde a su terror ante la vida... (El) espacio profano representa para el hombre religioso el no-ser absoluto» (2).

Presentamos a continuación una propuesta de comprensión del itinerario histórico de los grupos populares urbanos de Chile en el espacio de treinta años marcados por el sostenido avance de una occidentalización que niega la identidad social y espiritual de dichos grupos. ¿Cómo responde el pueblo? ¿Cómo reacciona frente al proceso de no-ser, al proceso profanador que encierra para ellos el dinamismo de Occidente?

Se proponen tres etapas en el curso de estos treinta años de lucha por la sacralidad, de superación del Caos económico, social o ideológico a través de la conquista de los espacios de lo sagrado popular. Hay un momento de fundación en los años 60, un momento dramático de defensa colectiva del mundo en los 70 y 80, y un tercer momento que comienza a perfilarse a fines de los 80 y que lo dejamos enunciado hasta 1992.

\section{Fundar un lugar sagrado 1962-1973.}

En procura de nuevos y mejores horizontes de vida, miles de hombres y mujeres ante los ojos de las ciudades «modernas» comenzaron a instalarse en los extramuros urbanos de Chile. Eran personas que provenían de las provincias rurales del país, con una identidad y una historia cultural ligada profundamente a los valores de la tierra. Poseían una sólida cultura campesina que, con dificultad, podía adaptarse a los criterios y valores de la sociedad occidental urbana. 
El paradigma civilizatorio de estos emigrantes era el modelo cósmico de la Tierra-Madre y, en él, las mujeres cumplieron un rol protagónico indiscutible.

El acontecimiento ritual, fundacional del momento fue la ocupación de tierras o «tomas de sitios» o «tomas de terrenos», lideradas por mujeres en un proceso histórico que podría ser comparado como una dinámica inversa a la de la Conquista europea del siglo XVI. Si ésta fue una empresa de preferencia de varones con objetivos de explotación mercantil, ahora se trató de una acción privilegiada de las mujeres con objetivos de reinstalar el modelo cósmico de la Tierra-Madre en un reto a la ciudad occidental.

La «toma de terrenos» fue la más emblemática y fundacional de las acciones destinadas a obtener un sitio donde vivir. Entre 1967 y 1972 unas 54.710 familias, el 10 por ciento de la población de Santiago, logró un terreno a través de las tomas. Esta experiencia llegó a un paroxismo en 1973 cuando en el primer semestre se contabilizó una toma de terrenos por día (3).

A veces sin el consentimiento de sus maridos, llevando sólo a sus hijos, las mujeres emprendieron las acciones que culminaron con el acceso a la tierra (4). Ellas también supieron contar esta historia con sus propias imágenes y sistemas de representación campesinos. Una mujer nacida en Sotaqui en 1911 compuso esta canción para celebrar una toma de tierras en Renca en 1969:

$$
\begin{aligned}
& \text { «El día primero de Mayo } \\
& \text { los sin casa de Renca } \\
& \text { se tomaron los terrenos } \\
& \text { para poder prosperar. }
\end{aligned}
$$

Cansados de tanta espera

que el gobierno no cumplía

toditos con altivez

lo hicieron a la luz del día.

Y van a seguir luchando

para poder conseguir

lo que tanto esperaban

para poder vivir.

\author{
¡Bajo la lluvia \\ todos unidos \\ corrieron sus banderas \\ gritando: tierra queremos! (5).
}

Llama la atención en los versos la oposición entre la inacción de las autoridades urbanas y el desencadenamiento de las fuerzas naturales que 
acompaña la acción de los pobladores a favor de la vida (luz del día, lluvia). Hay allí una visión cósmica que es esencial en esta fundación popular del Mundo.

Varias de estas poblaciones llevaron nombres de mujeres como Clara Estrella, Sara Gajardo, Violeta Parra, incluso el de una niña recién nacida durante la toma como Herminda de la Victoria. En sus propios espacios, una vez instalados en los terrenos, los pobladores «constituyeron formas de gobierno comunitario basta entonces desconocidas» (6).

¿Cómo vieron y calificaron estos emigrantes de arraigada cultura campesina y popular a los representantes de la cultura urbana dominante? Parecieron no existir criterios de emulación o admiración, al menos entre las mujeres. éstas estaban conscientes que ese mundo representaba lo profano, o lo profanador, lo no-sagrado. La mujer de Sotaquí que ya citamos decía en 1970: «No me gustaría ser rica, yo odio a los ricos y menos me gustaría ser rica» (7). Otra mujer de la población «Cuatro Vientos» de Santiago dijo en 1973: «El rico, ¿es el buen cristiano?. Esa es la pregunta que uno se hace. Hay tantos libros que dicen que el Paraíso no va a ser de los ricos, sino de los humildes» (8):

Un testimonio muy determinante lo proporcionó una «meica» o hechicera nacida en Colina en 1919 y que como habitante de la Población «El Esfuerzo» de Vitacura -una zona colindante con la de las élites urbanas- decía en 1970: «Conozco a toda esa gente de Vitacura. Son miserables, por eso tienen dinero; no tienen sentimientos pa' el próximo... Pa' mi que la gente de campo es la más güiena... La gente de campo no es miserable, no están contando cuánto se comió, ni cuánto no se comió... Los ricos son la peor gente, que harán lo que puedan para ellos, hasta matar por defender la plata» (9).

El sentido religioso-social de esta hechicera chilena es palpable:

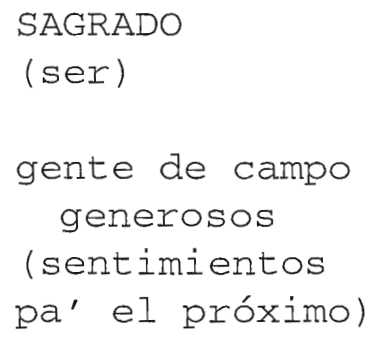

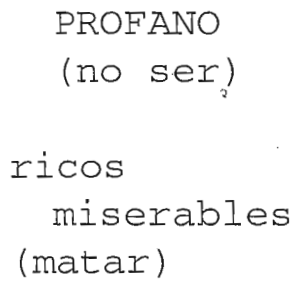

La población debía ser el lugar bendito donde se refundaran las costumbres propias del campo, su tradición ajena a las de las élites, de acuerdo a una ética matrística consonante con el modelo cósmico de la Tierra-Madre. En 1963 llamó la atención en un sector de La Granja, al sur de Santiago, la disposición de una pobladora de origen mapuche, Guillermina Paine, quien junto a su esposo adoptó a seis hijos además de brindar alimentación diaria a 
decenas de niños de su población. Sus argumentos empalman sin duda con la cosmovisión de la «meica» mencionada más arriba: «Tanto mi marido como yo hemos perdido a nuestra madre cuando teníamos apenas seis años. Nos criaron parientes ricos en dinero, pero pobres en cariño. Ambos, sin conocernos aún, decidimos desquitarnos algún día, dando todo nuestro cariño a los niños...» (10).

Con testimonios de esta índole se puede apreciar la conclusión que sacara el sociólogo Pablo Hunneus acerca de los pobladores de Santiago en 1963: «No comparan su suerte a la de la población urbana, no la envidian ni demuestran deseos de imitarla» (11).

Los pobladores estaban forjando un mundo propio con sus particulares creencias y costumbres sociales y religiosas, y sus «mezclas» impracticables para la cultura dominante. Las convicciones religiosas de origen rural acerca de la Virgen como símbolo de la Tierra-Madre se relacionaron sin dificultad con las adhesiones políticas al Partido Comunista en una común cosmogonía popular. En 1965 el XIII Congreso de dicho partido en Chile reconoció que los pobladores de Santiago al celebrar las «tomas de terrenos» afirmaban que se lo debían por igual al Partido y a la Virgen (12).

La toma de tierras no era un acontecimiento meramente político como podría entenderse desde Occidente. Era un evento fundamentalmente religioso, un paso del no-ser al ser. Como relata Guillermina Farías acerca del origen de la población La Victoria: «Se parecía al pueblo de Israel en busca de la tierra prometida: los dirigentes eran los profetas de esos tiempos» (13).

¿Dónde encontraban los pobladores las fuentes de su propio misticismo? De acuerdo al modelo de la Tierra-Madre alcanzaron una singular importancia las «meicas» o hechiceras por sus conocimienos de la naturaleza asociados a prácticas rituales. Estas tradiciones campesinas centenarias reaparecieron en las poblaciones como un desafío a los círculos de la medicina y la religión occidentales. La «meica» de Vitacura que citamos se reconoce en una vasta tradición campesina: «Mi abuela sabía de las brujas también y otras cosas de espíritu... (A mi) me gustaba curiosear en todo eso de meicas... Siempre me ha gustado no se por qué estas cuestiones de mágicas... Dios anduvo en la tierra y dejó las yerbas pa' nosotros los pecadores. La gente de campo se mejora con puros remedios de las meicas como yo... (Sólo) las personas ricas creen en los puros doctores no má!» (14).

Desde esta comprobada sabiduría campesina la percepción más aguda del carácter profanador de Occidente tuvo lugar con ocasión de la penetración misionera católica en los años 60. ¿A qué iban estos clérigos «gringos»o burgueses en dirección a los espacios donde el pueblo creaba su mundo propio?.

El fundador de la parroquia de San Pedro y San Pablo en un sector poblacional de Santiago en 1964, el P. Esteban Gumucio SSCC, pudo escuchar de los mismos pobladores su versión de esta expansión eclesial: «La Iglesia 
viene a las poblaciones por la plata. Eso era lo más común. Lo segundo, a tener las mejores mujeres. Lo tercero, porque eran maricones» (15).

Eran los conceptos históricos de la cultura popular y campesina de Chile acerca de la tradicional Iglesia Católica (16).

Especialmente los misioneros «gringos» con su versión occidental del cristianismo fueron vistos como una amenaza de profanación religiosa. El P. Antonio Ghyselen, sacerdote belga llegado al país en 1965, reconoció esta visión en 1971 (17).

Los pobladores defendieron sus particulares visiones de lo sagrado. Sus costumbres, sus creencias, sus mujeres y, por sobre todo, su tierra, como una propiedad común sin privilegios de ninguna especie. En la toma de tierras de La Victoria llegó a apedrearse al sacerdote Del Corro porque proclamó dos sitios para instalar su Iglesia. En 1963 los pobladores de La Victoria expulsaron al sacerdote del territorio por su actitud clasista y discriminatoria. Según recuerda una mujer del lugar: «El cura trataba de comprarse y dividir a los pobladores, como un vendedor que vende pan. Lo echamos fuera en 1963. Había pan para todos o si no para nadie» (18).

Los símbolos religiosos populares se articulaban en torno a la figura indiscriminatoria y no-jerárquica de la Tierra-Madre, traída desde la cultura rural y reivindicada en los espacios de los extramuros urbanos. Esta figura se encarnó, como decimos, en la imagén de la Virgen con sus cultos domésticos a través de grutas familiares o celebraciones populares del mes de María en el contexto regocijante de la primavera. La Navidad como representación ancestral de la Virgen y el Niño Dios tuvo también una singular comprensión en el marco de las «tomas de terrenos». Según el testimonio de la «historiadora» de la Población La Victoria, Guillermina Farías: «Esa Navidad fue inolvidable; no podía haber mejor regalo navideño que cada uno en su sitio, que para muchos era el primero de su vida. No había luz eléctrica pero estaba la luz de la esperanza» (19).

Desde esta simbólica matrística las pobladoras lograron acoger a las misioneras o religiosas que pudieron asociarse a la gesta/gestación de la vida en los territorios recién conquistados. No hubo en este caso la amenaza enajenante que se percibió en el clero. Entre todas, aunque las religiosas fueran «gringas», se podía fundar el lugar sagrado del pueblo (20).

En el contexto de esta vida que emergió en las poblaciones debe entenderse el triunfo popular chileno de 1970. Como escribió el filósofo Luis Oyarzún tras los resultados del 4 de septiembre: «Los ganadores de esta batalla electoral no son propiamente los políticos, ni Allende, ni los comunistas ni los hombres de partido... Han triunfado los jóvenes y los sin casa... Lo que pugnaba por emerger, siempre con triunfos o derrotas a medias, ha abierto hoy la brecha» (21). 


\section{Defender un lugar sagrado 1973-1986.}

Entre 1973 y 1986 tuvo lugar un proceso histórico excepcional para los pobladores consistente en defender su mundo ante la discriminación económica, social y cultural promovida por el Estado militar. Este Estado se definió en su sentido altamente excluyente con relación a los habitantes pobres de la ciudad, quienes fueron vistos comno seres insatisfechos, sobrantes, peligrosos, a los cuales había que apartar o desintegrar.

Las autoridades políticas de la época buscaron hacer perder toda identidad propia a los pobladores que habían fundado su lugar en la ciudad hasta 1973. Cambiar de nombre a las poblaciones, erradicar grandes masas -entre 1980 y 1985 fueron erradicadas en Santiago alrededor de 150.000 personas-, desatender a las necesidades elementales de los pobladores, fueron situaciones que se hicieron sentir trágicamente hasta los años de las grandes protestas ocurridas entre 1983 y 1986, donde aún las manifestaciones populares fueron ahogadas por la represión armada. Entre mayo de 1983 y mayo de 1984 solamente en el sector de Pudahuel en Santiago las Fuerzas Armadas dieron muerte a diez pobladores (22).

En este contexto los pobladores recurrieron a diversas respuestas que tenían una raíz religiosa indudable. Tras las diferentes acciones políticas, económicas o culturales emprendidas estaba la motivación religiosa elemental de resistir al Caos y la muerte. Todas las actividades adquirieron una fuerte carga mística, dado el decidido carácter profanador de los que representaron las instituciones tradicionales de Occidente.

El modelo civilizatorio de los pobladores, ¿continuó estando inspirado en la imagen ancestral cósmica de la Tierra-Madre? La importancia del protagonismo femenino, el valor de las organizaciones comunitarias, la valoración de los símbolos de identidad indígena, etc., indicaron hasta cierto punto la persistencia de la matriz cultural básica de los pobladores y su capacidad de revitalización en el contexto social de la época.

Entre las significativas muestras de organización popular de esos años se apreciaron instituciones que agrupaban exclusivamente a mujeres pobladoras como el movimiento de Mujeres Pobladoras (MOMUPO) nacido en 1981. En 1985 se contabilizaron en Santiago 436 organizaciones compuestas sólo por mujeres pobladoras (23). La expresión social más relevante de la defensa sagrada del mundo poblacional fue, con todo, la acción comunitaria. Cientos de estas acciones dieron lugar al surgimiento de organizaciones populares como Comedores Infantiles, Ollas Comunes, Grupos de Salud, Comprando Juntos, etc., destinadas a cubrir las necesidades básicas de una población cercada por el modelo económico liberal del régimen militar. 
Esta fue la reacción sagrada por excelencia de los pobladores -y sobre todo liderada por las mujeres- según el modelo igualitarista y cósmico de la TierraMadre. Este modelo no respondió a esquemas políticos occidentales sino a intereses ancestrales de proximidad humana -los «sentimientos pa' el próximo» de que hablaba la hechicera de Vitacura en 1970. Esta lógica puede percibirse en las palabras de Nelly Gallegos, pobladora de La Victoria y madre de un hijo asesinado por Carabineros en 1984: «Sé que los carabineros mataron a mi hijo, pero yo no los odio, porque el odio es tremendo, corroe a las personas. Eso no significa que me conforme frente a la injusticia, lo que hago es dar lo que veo, organizarse junto a otras mujeres y trabajar para que no pase lo que pasó cuando hirieron a mi hijo, que no había ni un botiquín cerca. Yo veo en cada carabinero a un ser humano. Por eso mismo sé que pueden entender si nos acercamos y les hablamos, si se dan cuenta que no los odiamos como piensan. Así no tienen justificación para odiarnos a nosotros» (24).

El modelo de la Tierra-Madre fue el que guió en cierto sentido las grandes manifestaciones de protesta en un clima festivo y carnavalesco -de afirmación de la vida para todos- que buscaba exorcizar las fuerzas de la muerte. Hablando de las protestas en la Población Herminda de la Victoria en los años 80 señalan unos autores: «Muchas poblaciones se convierten por un día en territorios tomados, en los que se desatan verdaderos carnavales y en muchos de los cuales el Ejército y Carabineros no pueden entran» (25). Una crónica del primer aniversario del Campamento Fresno describió en 1984: «Todavía llevo adentro el pequeño carnaval de ayer, expresión de fiesta de un pueblo que en medio de sus carencias y sus sufrimientos, sabe celebrar y disfrutar a su manera... El pueblo, en medio de tanta injusticia y humillación, sabe CELEBRAR LA VIDA» (26).

La literatura poblacional de esos años reflejó muy bien esta vitalidad según las imágenes del cuerpo activo y colectivo del pueblo. En el poema Itrokom Mapu Rupam - Por todas las Tierras pasaremos compuesto en un taller cultural de la Población La Legua en 1985, hallamos este sistema de representaciones poéticas:

\author{
«Que se hablen las bocas \\ que se junten \\ que se muerdan \\ que se abran demasiado \\ y se muestren a sus dueños. \\ Que se rían \\ que se besen las bocas/.../ \\ que reclamen las bocas \\ que hagan huelga de hambre \\ paro nacional/.../ \\ Que se rían \\ que se alimenten \\ que crezcan las bocas» (27).
}


Comunitarismo, apelaciones indígenas: reproducción y persistencia de un modelo ajeno a la profanidad de Occidente, especialmente entre mujeres y jóvenes, dos sectores claves de la convivencia poblacional.

¿Cuáles fueron las tradiciones espirituales más influyemntes entre los pobladores de la época? ¿Alcanzaron las lógicas misioneras occidentales católicas o protestantes- a trastocar el universo ancestral rural de los pobladores? La tradición religiosa de origen rural y cósmico, con sus devociones a la Virgen, su culto a los difuntos, y su casi nula vinculación a las Iglesias, siguió siendo una experiencia fundamental. Un estudio sobre las creencias de los pobladores de la zona Oeste de Santiago señalaba que un 45 por ciento de la muestra obedecía a dicha definición de lo sagrado en 1982 (28). La importancia simbólica de la Virgen se puede reconocer incluso en el porcentaje de evangélicos que admitieron concurrit a santuarios marianos (29).

El culto a los muertos, sobre todo a través de la devoción a las animitas, fue una esperiencia religiosa valorada y sancionada por las tradiciones domésticas. A través de sueños, los pobladores comprendieron el valor de ese culto para la integridad de sus amenazadas vidas (30). Los luctuosos acontecimientos que debieron enfrentar los pobladores -sobre todo durante las protestas de 1983 a 1986- dieron un nuevo sentido a este culto a los muertos acogidos por la TierraMadre. Las animitas, y aún más los velatorios, fueron emblemas colectivos y populares de unas vidas tronchadas pero que continuaban defendiendo los lugares sagrados (31).

Las creencias ancestrales sobre la renovación y fecundidad de la TierraMadre -como el nacimiento de Cristo- adquirieron un cariz especialmente luminoso para una cultura popular urbana que requería de sus propios ritos ante la devastación política de la época, como puede advertirse en estos versos de la poetisa Griselda Núñez, «La Batucana», que dieron pie a una representación teatral poblacional en 1980:

«En mitad de la noche hermosa

florecieron los arbolitos

cantaron los pajaritos

danzaron cactus y rosas

cobraron vida las cosas

la gente se levantó.

Al Mesías que nació

cantaron los pobres del mundo

y con sentimiento profundo

la esperanza se reafirmó.

Herodes mandó a Pilatos

Pilatos mandó a su gente

pero a dos mil inocentes

hicieron pagar el pato, 


\begin{abstract}
el más terrible mal rato
pasó el puebloo oprimío

El rey Augusto era bandío

que al mundo causaba horror

sembrando odio en vez de amor

mató a los recién nacíos» (32).
\end{abstract}

La celebración de la Navidad en las poblaciones dio lugar al festejo de las propias esperanzas de los pobladores. En Herminda de La Victoria en 1980 la Navidad fue la ocasión de festejar el restablecimiento del autogobierno democrático con el respeto al contrato original de vivienda que quisieron desconocer las autoriades gubernamentales. En la fiesta participaron 2.500 niños y todos los pobladores contribuyeron con algo (33).

Los días festivos y sagrados en el calendario del pueblo de origen campesino adquirieron una nueva significación en el contexto de la defensa del Mundo. No pudo ser casualidad que para la fiesta de las «Cármenes» se iniciara la Olla Común en la Población Intendente Saavedra del Cerro Navia. Segun el Testimonio de Sara Garcés, organizadora de la Olla Común, y emigrante desde Osorno a Santiago en los años 60: «Se le puso la Olla Común 'El Esfuerzo'... Hacíamos dos turnos de 50 lotros de comida. Empezó un 16 de Julio, día de las «Cármenes»...(34).

El hecho más notable de la época fue que los pobladores en esta coyuntura ocuparon los espacios de la Iglesia católica, imprimiéndole un sentido a partir de sus propias necesidades materiales y espirituales. Venciendo obstáculos y reticencias por parte de los «agentes de pastoral», especialmente clérigos, los pobladores desarrollaron su movimiento político y cultural bajo el alero de la Iglesia. Si en el periodo 1962-1973 los pobladores se tomaron las tierras de las periferias urbanas, ahora entre 1973-1986 los pobladores se tomaron en cierto sentido las Iglesias de las periferias urbanas con el objeto de convertirlas en imágenes vivas de la colectiva, indiscriminatoria y acogedora Tierra-Madre.

Esto constituyó una tensión constante. Los sacerdotes y autoridades de la Iglesia católica debieron lidiar costosamente consigo mismos y con los pobladores tratando de preservar su especificidad o alteridad religiosa e institucional frente a un mundo que los solicitaba con toda su efervescencia y diversidad en sus intentos de defenderse. No fue fácil que la Iglesia condicionada por sus particulares visiones de lo sagrado y lo profano- acogiera la propia defensa del mundo poblacional como una defensa sagrada. Al fin, sin embargo, se imponían los intereses populares. Según una propia narración histórica de los habitantes de la Población Clara Estrella: «El grupo América Joven..., encontró alero, no con poca dificultad, en la Iglesia católica, ya que se presentó como un grupo no cristiano. Integró la coordinadora juvenil de la parroquia y de allí salió la primera actividad de tipo solidaria en beneficio de los niños del Comedor Infantil, el 12 de diciembre de 1976 en el local del Club Soberanía» (35). 
Los sujetos que más resueltamente intentaron transformar de este modo la Iglesia fueron las mujeres y los jóvenes. Estos últimos conquistaron las instituciones católicas existentes, $y$, en cierta forma, las modelaron a imagen y semejanza de su cultura. Un ejemplo característico en este sentido fue la importante Comunidad San Bernardo dependiente de la parroquia San JoséGarín que administraban los misioneros norteamericanos de la Congregación de la Preciosa Sangre en la zona Oeste de Santiago desde 1948. En manos de los jóvenes pobladores la Comunidad se abrió a todas las dimensiones de la vida sin exclusiones ni etiquetas confesionales durante los años 80 . Como recuerda uno de sus dirigentes: «Deseos de participar, deseos de ocio, deseos de gozar, todos esos deseos para nosotros eran válidos. Que nos quedáramos en la noche en una vigilia, y tomándonos un trago, y rezando era bueno. De repente cien cabros, ochenta cabros en el patio, rezando con una fogata, cantando canciones del Víctor Jara, o cantando canciones de la Iglesia, y afuera milicos. Al final, lo que estábamos haciendo: ¿qué sentía yo? Un acto de amor puro no más. Y en ese acto de amor puro habían marxistas, habían creyentes, no-creyentes, (personas) que venían aquí por pinchar (buscar pareja), otros por pasarlo bien, otros por entretenerse. Al final, era como un bien común no más» (36).

El protagonismo social y espiritual de los pobladores fue capaz de transformar en cierta medida a la Iglesia católica, alejándola al menos en ese momento, de sus estereotipos occidentales. La figura del obispo auxiliar de Santiago Don Enrique Alvear, vicario de la zona Oeste entre 1975 y 1982, quien reconoció que los pobladores le habían enseñado a ser pastor, constituye un símbolo indiscutible de esta inversión de roles a favor de la defensa de la vida sagrada del pueblo (37).

\section{Habitar un lugar sagrado 1986-1992.}

Con el fin de las protestas masivas, el rechazo al gobierno militar en el plesbicito de 1988 y el restablecimiento de un gobierno civil en 1990, el mundo de los pobladores inició una nueva etapa en su evolución histórica que creemos todavía en curso. A pesar de ser, entonces, un proceso inacabado y por lo mismo impreciso, creemos necesario señalar las tendencias culturales y espirituales que comienzan a percibirse.

Con la gran movilización religiosa y política que significó la visita del papa Juan Pablo II a Chile -y su encuentro específico con los pobladores el $2 \mathrm{de}$ abril de 1987- se inició una suerte de revalidación de la historia de éstos más allá de la exclusión caótica iniciada en 1973. El célebre discurso de Luisa Riveros, de la Población Violeta Parra, mostró la fuerza de una cultura que concebía la tierra como un lugar sagrado a pesar de todas las profanaciones posibles (miseria, drogadicción, etc.). Ella se presentó como madre y, con ello, como símbolo de la Tierra-madre, el modelo cósmico que sostenía la vida de los pobres de la ciudad. 
¿No sería posible sostener más allá de los años oscuros de la administración militar la vida del cosmos en un proceso concebido como una «luna nueva»? ¿No vendrían nuevas generaciones a rehabitar la tierra y la vida incesante? Esta sensibilidad se advierte en los poemas de Angélica Cornejo, pobladora de La Granja, publicados en 1993:

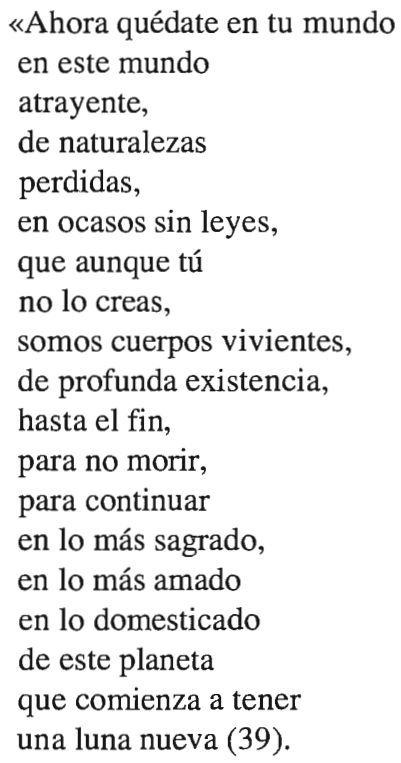

Se abrió, pues, un nuevo ciclo cósmico. En este sentido, los pobladores debieron comenzar a profundizar sus propias certezas, historias y místicas.

Nuevos hechos, nuevas respuestas. Los pobladores -y otra vez las mujeres y los jóvenes sobre todo- han comenzado a comprender el valor de sus propias tradiciones religiosas, más aún después de advertir la vuelta de la Iglesia católica a sus estereotipos tradicionales. En 1993 reflexionaba Doris Muñoz, una hija de campesinos avecindados en las poblaciones de Santiago, y que participó en actividades de pastoral en los 70 y 80: «A la Iglesia católica le veo un futuro de ghetto, como cada día de Iglesia cerrada... No veo que se vaya a acabar. No muere la Iglesia, pero va a morir en uno. Mi papá era de Parral. La religión de mi papá es de santos, de velas, de rosario. mi papá era para nada de Iglesia, porque era un campesino pobre. Por mucho tiempo yo pensé que yo era mucho más evolucionada que mi papá respecto de la fe. Y en el último tiempo como que estoy volviendo a la fe de ellos, en términos de tener una armonía mucho más grande, sobre todo los campesinos, de Dios con la vida, con el campo, con la creación» (39).

La misma Luisa Riveros, que colaboró con la Iglesia católica en los tiempos de Don Enrique Alvear, debió reconocer que dicha institución se apartó de las necesidades espirituales y sociales del pueblo (40). 
La juventud pobladora de los 90 difícilmente puede identificarse con las Iglesias que se han introvertido en sus discursos institucionales. Un joven mapuche de Cerro Navia, nacido en 1973, refirió en estos términos su sensibilidad religiosa en 1994. «La Iglesia es igual a un ejército. Está el papa que es el general, hasta los curas de acá que son los cabos. Y uno es el pelao (conscripto) cualquiera. Ni ahí con la Iglesia la encuentro cínica... (algunos) dicen que Dios es una fuerza, como creen los mapuches igual. Es una fuerza que está en el aire. Si fuera por eso, todos seríamos Diós, porque todos tenemos la fuerza que la transmitimos para afuera. A lo mejor, cada uno es Dios» (41).

¿La sacralidad está en uno mismo? ¿En las propias tradiciones? ¿Dónde está lo profano? El dirigente de la citada Comunidad San Bernardo Héctor Campos -nieto de unos pobladores que llegaron a Cerro Navia en 1966- revela el itinerario espiritual de muchos pobladores que procuran reconocerse en una historia donde una vez más, como en un principio, la «gente de campo» ofrece un referente inexcusable para una población que allí tiene sus orígenes:

«La Preciosa Sangre vendió la parroquia de San José en plata a los curas diocesanos. Les vendió la escuela, el templo, les vendió todo, con las personas incluidas. Eso ya pasó a ser aberrante. Cuando es vendida la Iglesia y llegan los diocesanos..., derechamente nos dicen que no podemos hacer ningún tipo de acción religiosa. En el fondo dejamos de ser Iglesia.

Yo creo en los mandatos de Jesús. Amarse los unos a los otros. (Y) lo que siempre he querido, y mucho, es sentir desde yo, y eso transmitirlo. Ojalá lo menos influenciado por otras cosas. (Pienso) que la gente de campo es resencilla, hacen sus reflexiones bien choras (valiosas). Dicen: no, yo no creo en la Iglesia católica. Ahí se roban todo, el cura se lima a las minas (abusa de las mujeres). $Y$ en los canutos (protestantes) tampoco, porque el canuto vive a costa de la gente. Yo creo en Dios no más, y a mi manera. En el campo se preocupan por lo que están viviendo ahora. Ahí siento que se junta pasado, presente y futuro. La visión de ellos es más mágica. Todo es más mágico. (Al hablar con ellos) es como un reencuentro de ver a mis taitas (padres) en este momento» (42).

Sin un interés mayor de generalización, puede advertirse que al cabo de treinta años de evolución histórica algunas grandes intuiciones de los pobladores han continuado vigentes en la larga duración, confirmando en cierto sentido las afirmaciones sobre la cultura popular del historiador Mario Góngora citadas al inicio de este trabajo. La sociedad occidental urbana con sus instituciones y su activismo siempre es percibida hasta cierto punto como un ámbito profano, sobre todo después de la experiencia profanadora durante los años del gobierno militar. Lo sagrado aun reside en los propios pobladores. Y de este modo continúan buscándolo (43). 


\section{NOTAS.}

(1) Mario GÓNGORA, «Proposiciones sobre la problemática cultural en Chile», Atenea, 442, (1980), p. 131.

(2) Mircea ELIADE, Lo sagrado y lo profano, Barcelona, 1979, p. 60.

(3) Armando DE RAMÓN, Santiago de Chile, 1541-1991. Historia de una sociedad urbana, Madrid, 1992, p. 298; Vicente ESPINOZA, «El movimiento de pobladores: una evaluación crítica», Proposiciones, 5, (1982).

(4) Teresa VALDÉS, Venid, benditas de mi Padre. Las pobladoras, sus rutinas y sus sueños, Santiago, 1988, pp. 82, 84, 174.

(5) Carmen PIMENTEL, Vidas marginales, Santiago, 1973, p. 111.

(6) Teresa VALDÉS, «El movimiento poblacional: la recomposición de las solidaridades sociales», Documento de Trabajo FLACSO 283, 1986, p. 8.

(7) Carmen PIMENTEL, op. cit., p. 112.

(8) Arthur COLGAN, Creencias populares sobre el problema del mal. Memoria Inédita. Facultad de Teología de la Universidad Católica de Chile. Santiago, 1973, p. 143.

(9) Carmen PIMENTEL, op. cit., pp.144, 146, 160.

(10) Ercilla, Santiago, 14 de agosto de 1963.

(11) Ercilla, Santiago, 11 de septiembre de 1963.

(12) El Siglo, Santiago, 16 de octubre de 1965.

(13) Guillermina FARJAS, «Lucha, vida, muerte y esperanza. Historia de la población La Victoria», Constructores de ciudad, Sur. Santiago, 1989, p. 57.

(14) Carmen PIMENTEL, op. cit., pp.122-3, 150-2, 155.

(15) Entrevista al P. Esteban Gumucio V. SSCC, Santiago, 5 de noviembre de 1993.

(16) Cf. «El cura que se adueñaba de las señoras casadas», Yolanda PINO SAAVEDRA, Cuentos folkloricos de Chile, Santiago, 1963, III, pp.139-142.

(17) «Cuántas veces al problematizar una u otra de sus creencias supersticiosas, hemos tenido que escuchar: Pero, padrecito; ¿usted me va a quitar mi fe!», Cf. 
Antonio GHYSELEN, «Para qué soy sacerdote?, Pastoral Popular, 121, (1971), p. 50.

(18) Cathy SCHNEIDER, «La movilización de las bases. Poblaciones marginales y resistencia en Chile autoritario», Proposiciones, 19, (1990), p. 235.

(19) Guillermina FARIAS, op. cit., p. 61.

(20) La célebre pobladora que le habló al papa Juan Pablo II en 1987, Luisa Riveros, recuerda a una religiosa canadiense en la Polación Violeta Parra hacia 1970: «A ella no le preocupaba la catedral, una capilla con mucho lujo. A ella le preocupaba que Jesús tuviera dónde vivir... La Madre María cuando teníamos que ir a la procesión del cerro, ella decía, vamos al cerro, porque vamos a ir a ver a la Madre de todos nosotros», entrevista a Luisa Riveros, 25 de noviembre de 1993.

(21) Luis OYARZUN, Diario, Concepción, 1990, p. 172.

(22) Cf. Hernán POZO (ed), Espacio y poder. Los pobladores. Santiago, 1987.

(23) Sara ALARCÓN, «Participación de las mujeres en las organizaciones poblacionales», CIDE, Santiago, 1990, p. 12.

(24) Boletín Zona Sur del Arzobispado de Santiago, III, 23 de noviembre de 1984.

(25) Lydia DE WOLF y Luis MOULIAN, Herminda de La Victoria. Aspectos Históricos, Santiago, 1990, p. 54.

(26) Boletín Zona Sur del Arzobispado de Santiago, III, 22 de octubre de 1984.

(27) Cit. James ROMANO (ed), Poética de la población marginal: sensibilidades determinantes, Minneapolis, 1987, p. 193.

(28) Cristian PARKER, «Creencias y cultura popular urbana», Mensaje, 312, septiembre 1982, p. 476.

(29) Cristián VIVES y Katherine GILFEATHER, Diagnóstico socio-religioso en ppoblaciones de San Bernardo, Santiago, 1982.

(30) Cristián PARKER, Religión y clases subalternas urbanas en una sociedad dependiente. Tesis Doctoral. Louvain, 1986, p. 365.

(31) Cf. Cristián PARKER, «Religión pupular y protesta contra la opresión en Chile», Concilium, 206, (1986), pp. 39-47. 
(32) Diego MUÑOZ y otros, Poética de la población marginal. El teatro poblacional chileno, 1978-1985, Minneapolis, 1987, pp. 283-286.

(33) Cathy SCHNEIDER, op. cit., p. 237.

(34) Entrevista a Sara Garcés, 3 de noviembre de 1993.

(35) Edison HERNÁNDEZ y Sandra VIVANCO, «Historia de la Población Clara Estrella», Constructores de ciudad, op. cit., p. 81.

(36) Entrevista a Héctor Campos, 25 de julio de 1994.

(37) Cf. Maximiliano SALINAS, Don Enrique Alvear: el obispo de los pobres, Santiago, 1991.

(38) TALLERES DE MUJERES POBLADORAS DE LA GRANJA, Conquistando espacios en versos, Santiago, 1993, p. 35.

(39) Entrevista a Doris Muñoz, 8 de noviembre de 1993.

(40) «No voy a la Iglesia, a ni una. Ni evangélica, ni católica, ni nada. realmente todas las cosas me molestan de la Iglesia ahora... Yo estoy con el Dios que está aquí en la tierrita junto con nosotros luchando»: Entrevista a Luisa Riveros, 25 de noviembre de 1993.

(41) Entrevista a Simón Aniñir, miembro del colectivo Newen Weche (Fuerza Joven), de Cerro Navia, 9 de noviembre de 1994.

(42) Entrevista a Héctor Campos, 25 de julio de 1994. Estas opiniones, como las anteriores, conceden hasta cierto punto la razón al juicio del historiador Ricardo Krebs en el sentido que las masas populares (chilenas) «no han podido ser conquistadas por la Iglesia (católica)», Cf. Ricardo KREBS, «Rasgos y manifestaciones del catolicismo chileno", Communio, 24, (1990), p. 75. En esta oportunidad hemos intentado dar una explicación acerca del fracaso de esta conquista.

(43) En este artículo bemos condensado algunas de nuestras conclusiones del proyecto FONDECYT 1930042-1993 titulado «La base popular y la Iglesia católica. El sentir de los jóvenes. Chile 1962-1992». 